This item is the archived peer-reviewed author-version of:

Pragmatized aesthetics: the impact of legitimacy pressures in symphony orchestras

\title{
Reference:
}

Herman Arne.- Pragmatized aesthetics: the impact of legitimacy pressures in symphony orchestras

Journal of arts management, law, and society - ISSN 1063-2921 - 49:2(2019), p. 136-150

Full text (Publisher's DOI): https://doi.org/10.1080/10632921.2018.1473311

To cite this reference: https://hdl.handle.net/10067/1535280151162165141 


\section{Pragmatized aesthetics: the impact of legitimacy pressures in symphony orchestras}

\section{Introduction}

"There is a nagging sensibility that we are living well beyond that authentic age of the orchestra and its repertoire", the American conductor and music scholar Leon Botstein once remarked (Botstein 1996). In recent years, symphony orchestras have indeed been struck particularly hard by declines in the cultural sector: drastically diminished government funding, a problematically homogeneous audience base, and an ongoing debate on the relevance of the institution itself are all symptoms of a field in crisis. Care must be taken in putting each and every orchestra under the same umbrella, but an overview of some of the world's leading symphony orchestras sketches a general picture of increasing precariousness (Ramnarine 2018). In the last decade, highly ranked North American orchestras such as Columbus Symphony Orchestra (2008), New York Philharmonic (2011), Detroit Symphony Orchestra (2010) and Philadelphia Orchestra (2011) announced they were near bankruptcy (Flanagan 2012). Private patronage, newly-obtained funding and financial injections via large sponsorship contracts have provisionally held off a graver demise of the institution, but the concern continues.

In contrast to most American orchestras, the lion's share of European orchestras relies on government funding; for up to 90 percent, compared to about 5 percent in the US (Flanagan 2012). Despite the de facto impossibility of bankruptcies within a system that strongly relies on government subsidies, the orchestral crisis has struck both supporting systems equally hard. In the Netherlands, the Philharmonie Zuidnederland replaces two former orchestras since 2013, and by 2026 the two Belgian federal orchestras will have melted into one, despite their very distinct artistic functions. British symphony orchestras have faced similar perils over the last decades (Sigurjonsson 2010; Galinsky and Lehman 1995), and even in Germany, with its very strong tradition of maintaining qualitative symphony orchestras, the number of orchestras and the amount of their subsidies has decreased over the last decades (Allmendinger and Hackman 1996).

The problem of unsustainable orchestras pairs with another noteworthy phenomenon that seems to permeate Western symphony orchestras. Around the globe, traditional symphony orchestras largely perform the same repertoire and adopt the same organizational structure: one chief conductor, a similar orchestral composition, a board of managers, ... (Glynn 2002). Many of the prominent orchestral institutions barely underwent any structural changes since the end of World War II. Now that their existence is under pressure, many symphony orchestras are renegotiating their place within today's civil society (Hamel 2016). Outreach programs and education projects are steadily becoming part of the DNA of many European and American orchestras (Galinsky and Lehman 1995), and the concert format itself is broadening as well. Connection with a globalized and non-hierarchical lifeworld is aimed for 
by means of film music concerts and cross-over concepts (Hamel 2016). Meanwhile, the musical repertoire that is presented in the traditional concert setting, escapes this innovation trend (see also: Hamel 2016, chapter 2). The 'classics' seem to dominate the concert programs more than ever. In this respect, today's symphony orchestras seem to have an ambiguous relation towards a globalising, market-bound world (see also: Flanagan 2012; Hamel 2016): economic globalisation seems to have paired with cultural stagnation and homogenisation, which has not yet been proven to be a sustainable formula. The bigger picture is that traditional symphony orchestras are increasingly being pressurized to explicitize what creates their current legitimacy. A variety of seemingly opposing alternatives for the orchestra's core business, has put many organizations in an existential quandary: is the orchestra's task limited to mere preservation of cultural heritage, or should an orchestra be an open and active forum for civil discussion? Should the orchestra focus on audience enlargement to guarantee increased revenue, or is an orchestra's total autonomy and isolation from mass culture the only way to secure music's integrity? And most of all: are these options mutually exclusive?

The answers to these questions are of course contingent, and relative to both timeframe and regional setting. It is indeed striking that the traditionally dominant strain of symphony orchestras is suffering the most (i.e. Western-European and American symphony orchestras, with a strong symphonic history and tradition), while relatively new orchestras in the Nordic and Baltic regions are flourishing (Vandyck 2016). Clearly, this situation is no black-and-white matter of market failure or success, let alone a question of artistic inadequacy. Rather, as Tasos Zembylas argues (Zembylas 2004), the legitimacy crisis touches on basic questions of society, because they involve different, often conflicting, objectives and values. Therefore, the aim of this article is not to provide categorical answers to the above questions, nor to make an empirical case report. Rather, I want to explore the dialectics between disparate factors in the orchestra's quest for legitimacy and show how these dialectics affect the orchestra's repertoire.

In extant literature, these phenomena are well-described in macrosociological as well as in aesthetic terms, but there seems to exist little middle-ground research that tries to link both discourses (a comparable observation is made by Hasitschka, Goldsleger, and Zembylas 2005). As a first phase of a larger research project investigating the sustainability of symphony orchestras, this article aims to provide an insight on how manifest macrosociological tendencies translate to the mesolevel of the art organization, which in turn influences aesthetic development. The complex environment in which art organizations move while producing and reproducing art will be mapped out in a model, proposed earlier by Pascal Gielen, that he called a 'biotope' (Gielen 2010). I will argue that the separate domains of this biotope require constant reciprocal interaction, for the organization to be sustainable. This closer analysis of the often omitted mesolevel wants to reposition this discourse within the reach of empirical investigation, without losing sight of macrosociological tendencies. Below, one example of this imminent empirical approach will be scrutinized theoretically, namely the 
performative act of music programming, which will be argued to be a significant part of a macrosociological context in which organizational and aesthetic concerns converge. By exposing reciprocal and often even ambiguous relations within the biotope model, this article offers a comprehensive framework for theoretical understanding, and proposes a new analytical approach that opens the way for empirical research that relates to the prospect of the sustainability of symphony orchestras.

\section{The symphony orchestra and its biotope}

To understand its behaviour, an organization can be framed within a social and institutional context that regulates practices and stipulates a certain norm for good or successful behaviour (Kraatz and Block 2008; Kremp 2010; Zembylas 2004). Expecting to gain legitimacy, organisations are inclined to align their organizational structure and value sets to that norm, especially in times of uncertainty. In this context, legitimacy can be defined as "a generalized perception or assumption that the actions of an entity are desirable, proper, or appropriate within some socially constructed system of norms, values, beliefs, and definitions" (Suchman 1995). Plainly, an organizational profile is a product of implicit (spontaneous) or explicit (strategic) exchange with a competitive or associated environment. Paul DiMaggio affirms: "Organizations compete not just for resources and customers, but for political power and institutional legitimacy, for social as well as economic fitness" (DiMaggio and Powell 1983). As this Darwinistic observation suggests, organizations have divergent and often opposing value regimes. The main challenge of every art organization is to reach a sustainable equilibrium by managing these inherent pressures. Accordingly, choices have to be made, and choices often entail compromises (Zembylas 2004). Ongoing research increasingly acknowledges the importance of the fact that cultural institutions are the point of intersection between cultural, social and economic interests, and stresses the need for an adequate conceptual model (Hasitschka, Goldsleger, and Zembylas 2005).

The problem of opposing tensions is adequately formalized in the so-called 'artistic biotope', a model proposed by the cultural sociologist Pascal Gielen. After doing inductive field research in numerous international art organizations, Gielen constructed a biotope consisting of four domains between which art organizations navigate (Gielen 2010). These four domains are the outcome of two intersecting axes that each represent a crucial disunion within art organizations. The development-oriented and investigative approach of every self-respecting art organization contrasts with a showcase-and-trade-approach, or product-oriented approach, that is necessary to keep the organization up and running. A second distinction concerns the degree of embeddedness of the organization in a professional network. The more an art organization is connected to a network, the more it will accommodate to the social pressure to adapt the organizational profile, or its set of strategies, to this network (see 
also: DiMaggio and Powell 1983). When both axes are crossed, a four-quadrant space emerges, as is shown in Figure 1.

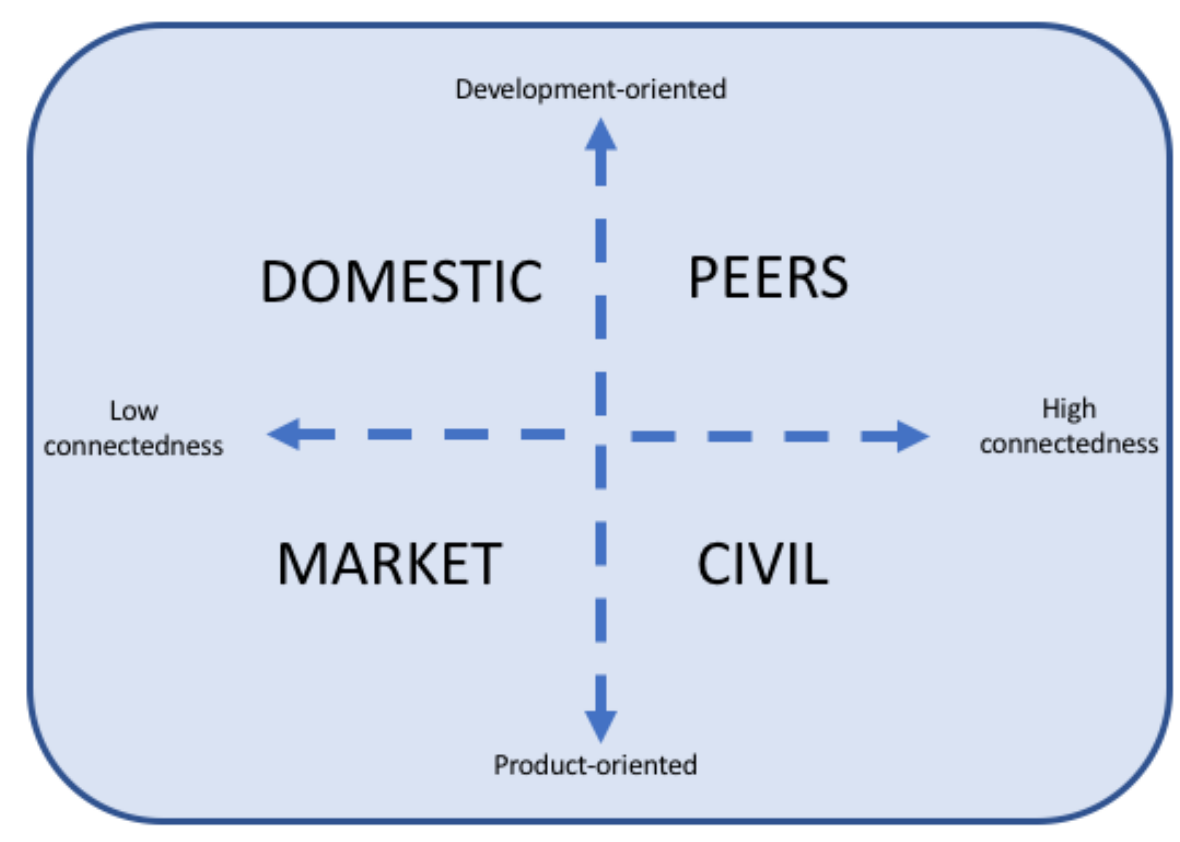

Figure 1: the artistic biotope and its domains (Gielen 2010)

Each of the four domains adheres to a certain logic, imposes norms on the organization and begs for well-considered choices that affect any other of the domains. In other words: the adopted balance between the four domains shapes the organization's profile.

-In the Domestic domain, art is developed and preserved in the most intimate, uncontaminated way. The logic of this domain is a fundamentally artistic and expressive one, unresponsive to anyone's appreciation. Translated to the analysis of the symphony orchestra: in the Domestic domain, the symphony orchestra has the potential to design an idiosyncratic musical language (be it experimental or upright traditional) that may only be supported by immediate associates or a group of intimates with the same personal taste, i.e. the orchestra itself and its immediate followers. In his famous book Art Worlds, Howard Becker calls these actors 'the mavericks': they are hardly conscious or even careless of what's going on in the musical world around them and "they propose innovations the art world refuses to accept as within the limits of what it ordinarily produces" (Becker 1984, p. 233).

-In the domain of the Peers, art is criticized, discussed, interpreted and developed in implicit dialogue with a group of specialized equals who share a similar aesthetic framework. In this domain, personal taste is sampled to the taste of what is generally accepted among peers. Here, the symphony orchestra meets its equals, be it as rivals 
or as associates, and reflects on its aesthetic position among them and in the musical community. Copy behaviour ("Our rival orchestra employs an experimental composer in residence, so let's do that too!"), attuning behaviour ("Our neighbour orchestra will program Bruckner's unfinished Ninth Symphony in a recently completed edition next season, so we shouldn't") and dissociating behaviour ("Our neighbour orchestra turns to exotic repertoire, so we will emphasize our conservative profile"), all belong to the domain of the Peers.

-The Market domain arguably adheres to the most straightforward logic. Here, art is produced and reproduced from a profitable point of view, and social interactions are reduced to economic transactions. Contrary to intuition, embeddedness in a professional network is low in the Market domain: this domain only sets up a consumption-relation, without accountability in terms of artistic content. The symphony orchestra accordingly positions itself as a player in a competitive market, where revenue is key.

-Finally, the Civil domain is where art becomes culture. Art organizations are, from the viewpoint of the Civil domain, considered as agents of cultural values and, because of their possibility to generate or provoke order and disruption, as media for reflection on society. Following the logic of the Civil domain, the orchestra is an effectual voice in society and a widely accessible forum for reflective contemplation and judgment on matters that affect the community in the broadest sense. The art organization can go as far as to find political legitimation in the Civil domain. Here, a profitable choice for the orchestra would be the publically defendable one. Therefore, the degree of embeddedness in a network is high in the Civil domain. Decisions are made in the light of a reciprocal relation with an audience in the widest possible sense: as a society.

Gielen urges that one shouldn't regard both binary opposites that create the four domains, as mutually exclusive. In the biotope itself, the four domains have to be considered each other's complement at all times, and each domain implies the presence of the other three without any a priori notion of hierarchy or causality. To isolate one of the domains, as this article sometimes does, only makes sense from an analytical point of view, and any hierarchy among the domains will be the outcome of a conscious or unconscious choice of the organization. The Domestic domain, for example, can easily be acknowledged as the most 'romanticized' of all four domains. If the artist, or in the present case an art organization like a symphony orchestra, opts to develop and exclusively cultivate an idiosyncratic musical idiom, without reference to any previous and peer-adopted loci (granted that such would be possible), there will be no aesthetic expressiveness, nor market value or civil interest (see also: Hasitschka, Goldsleger, and Zembylas 2005). In that case, the artist or art organization will suffocate and the art product, as Gielen bethinks, will be reduced to a means for auto-therapeutic activity. In a similar vein, Werner Hasitschka (Hasitschka, Goldsleger, and Zembylas 2005) argues that, 
from a market-oriented point of view, cultural goods are treated in the same way as commodities, and that fruitful exchanges of cultural ideas seldom occurs. At the same time, the artist cannot do without the exchange value of his art. The biotope model conceptualizes these ambiguous and fragile tensions. According to the biotope model, any art ripens via the social transactions that one finds in the Civil or Peers domain (see also Becker 1974), as well as via economic transaction one finds in the Market domain.

A second example can be found in the ambiguous consequences of subsidizing, which is particularly common in European symphony orchestras. The main rationale behind subsidies is, translated to biotope-terminology, to safeguard the artistic mission of the orchestra by shielding the development-oriented Domestic domain from the blind forces of the competitive Market domain (see also: Zembylas 2004; Hamel 2016). By guaranteeing a basic financial stability and independence, the orchestra is supposed to be able to develop itself in any aesthetic direction and to profile itself accordingly among other orchestras. In practice, the opposite is often the case. Because not every single orchestra can be subsidized, orchestras who are in the running tend to mimic the strategic choices of their peers (often those who managed to receive subsidies in the past), to purchase legitimacy (Glynn 2002). As a consequence, the competitive nature of the subsidizing system doesn't unequivocally lead to differentiation in aesthetic preferences and organizational forms, but often instigates competitive isomorphism among peers, resulting in aesthetic accordance and organizational uniformity (see also: Zembylas 2004), neither of which can be fully reconciled with the Domestic domain.

The insight that isolation from a larger civil platform isn't a productive choice, can count as a third example: as earlier research shows, successful artists or symphony orchestras obtain more creative freedom with their success and profits, and their audience base is likely to be more receptive to these creative variations (Kremp 2010; Turrini, O'hare, and Borgonovi 2008). This way, the Civil domain (where success can be a parameter) and Market domain (where profits can be a parameter) hold the possibility to indirectly affect aesthetic innovation. Together, the four domains envelop the possibilities and necessities for a healthy art organization. Adequately governing the tensions that arise from the domain's distinct dicta, amounts to optimizing the possibilities that each domain itself generates for the organization. That is: to develop (Domestic domain), discuss (Peers domain), produce (Market domain) and showcase (Civil domain) art.

While this framework might seem rather static or reductionist at first glance, it maintains a considerable amount of flexibility. Firstly, the biotope is a model that contemplates the complex relations between the various domains, not the domains in themselves. Each of the domains generates possibilities for the art institution, but a careless focus on one domain can lead to crises in the other domains. Coincidentally, a shift or crisis in one of the domains, like a cutback in subsidies or the emergence of a new musical idiom, will immediately affect the 
other domains as well. Secondly, the biotope provides an adequate tool for research on art organizations because it respects the aesthetic considerations as well as the pragmatic ones, and because it allows us to map and visualize deliberate and undeliberate choices of art organizations and the implications of those choices. And finally, it has been proven to be empirically applicable and valid in a large set of different art institutions (Gielen 2009, 2010). In short: the dynamics between macrosociological tendencies and empirical consequences can be assessed and visualized by means of this biotope model. In the remainder of this article, I will dissect the issues at stake and turn to the biotope for their deeper understanding.

\section{Utilitarian legitimacy: the compromise of the musical canon}

The orchestra's struggle for legitimacy shows that the root of their decline in sustainability is not primarily musical in nature, but social (see also: Botstein 1998). The first social changeover that comes to mind is a decreased exposure to classical music, partially as a result of the orchestra's failure to adapt to macrosociological changes (Hamel 2016). Since the rise of the institutionalized symphony orchestra as we know it (in the second half of the twentieth century), most of the secondary institutions where musical tastes were stimulated, like church and education, have altered drastically, whereas, paradoxically, the symphony orchestra has crystallized (Botstein 1996). There is, however, a deeper context to this coordination problem. Mary Ann Glynn asserts that conflicts over legitimacy (which she calls 'identity') easily translate to conflicts over crisis management: legitimacy issues bring into conflict the dual elements of economic utility (where financial return symbolizes success and grants legitimacy) and normative ideology (where artistic creativity and excellence symbolize success and grants legitimacy) (Glynn 2000). Various studies agree that economic crises in particular tend to favour the business mentality within an art organization (Glynn 2000, 2002; Kremp 2010; Ramnarine 2011; Hamel 2016). Problems regarding income and resource acquisition like subsidizing money or private funding prompt managers to favour predictability over uncertainty (for a historical approach, see DiMaggio and Powell 1983). The resulting organizational isomorphism has been touched upon above, but this turn to predictability has reverberations on other aspects of the organization as well, that are not necessarily associated with organizational stability (Galinsky and Lehman 1995).

In terms of predictability, the artistic programming of a certain widespread and unquestioned standard is the safer choice. In the case of music, this standard repertoire or 'musical canon' can be defined as a stable body of musical works, spanning the time period between roughly 1780 and 1910 (Weber 1999), that over time persistently survived spontaneous and conscious selection processes. Beethoven's Fifth Symphony is the preeminent example, as well as symphonic works by (among few others) Mozart, Mendelssohn, Berlioz, Brahms, Tchaikovsky, Wagner, Bruckner and Strauss. The initial benefits of programming the canon in symphony orchestras are threefold. Firstly, because of the widespread familiarity with the performed 
works, audience numbers rise and so does ticket income: reproduction of the canon increases revenue significantly (Kremp 2010). Furthermore, because of performers' familiarity with the repertoire, the required rehearsal time for performances is far less than the time needed to perform contemporary or peripheral works (Gilmore 1993). Secondly, this dilemma of box office success and shrinking public can be averted without having to compromise a certain aesthetic standard. Due to their unquestionable status, canonical works seldom face opposition from a musician's or a critic's side. Because the aesthetic focus shifts towards performer's activities instead of the compositions themselves, judgment over the value of performances becomes far more easy and accessible. The pragmatic avoidance of creative risks thus causes creativity to be redefined as virtuosity in interpretation of the standard repertoire (Gilmore 1993). Research shows that orchestras have indeed become less likely to perform newly written compositions over time (Kremp 2010; Osborne 1999).

\section{Civil legitimacy: the paradox of the musical canon}

Frequently, the legitimacy claim of symphony orchestras relates to their alleged beneficial impact potential (Hamel 2016). It is a popular belief that music has a constructive social impact on those involved as practitioners or as audience. Being a welcome legitimation for an art institution that has been enduring an existential crisis for a long time, there remains little room and even littler demand for ambiguity of the social impact of classical music. The strong emphasis on the musical canon in today's symphony orchestras is an attempt to balance aesthetic interest against pragmatic reality, but this process of selection also conceals a sociological, even ideological background. Art institutions like the symphony orchestra have a symbolic cultural value: while adhering to a certain norm, they disseminate those norms beyond the boundaries of any specific organization in the form of what Bourdieu called 'cultural capital' (Bourdieu 1986). Paul DiMaggio echoed:

\footnotetext{
"For a society to have cultural capital - sets of cultural goods and capacities that are widely recognized as prestigious - there must be institutions capable of valorising certain symbolic goods and social groups capable of appropriating them." (DiMaggio 1991, p. 135)
}

The point that Bourdieu and DiMaggio make, is that art institutions and the values they adopt, are related to behaviour of social bodies. Translated to the current focus: there is a causal relation between the adoption of a musical canon in symphony orchestras (DiMaggio's 'symbolic goods'), and social structures (see also: Bergeron and Bohlman 1992; Hasitschka, Goldsleger, and Zembylas 2005).

The musical canon, as insinuated before, is a hierarchical principle of order: it presents old works organized as a coherent collection, and defines sources of authority with regard to 
musical taste (Weber 1999). Remarkably, during the canon's process of reification in the beginning of the $20^{\text {th }}$ century, non-canonical works where frequently disregarded merely on the account of their non-canonical-ness. Precisely because of this new sense of severe hierarchy in art, canonical music strongly appealed to the higher bourgeoisie, struggling for its collective identity by the end of the $19^{\text {th }}$ century (Weber 2002). Following Bourdieu's and DiMaggio's logic of cultural capital: those social groups capable to appropriate the institution and the values to which it explicitly or implicitly adheres, achieve a higher social status. Indeed, art music was appropriated by these higher classes and was used to emphasize social differences within modern society; an objective to which the musical canon lends itself quite well. Once an authority on taste is made into a standard, as is the case in the emphasis on the musical canon in symphony orchestras, its values become internalized and are no longer called into question (Bergeron and Bohlman 1992). The implied social hierarchy that is present in the process of musical selection, conflates with the canon itself and becomes a cultural selfevidence. Thus the canon became, and remains to this day, an important resource for legitimation of the institution that carries it forward (i.e. the orchestra), precisely because it constitutes and represents cultural capital (see also: Turrini, O'hare, and Borgonovi 2008). But can this form of cultural capital, represented by a musical canon that has remained nearly unaltered for the last century, be reconciled with modern society?

The growing affirmation and acceptance of the social relevance of the orchestra as a musical institution, embodied by their expanding outreach and education programs, stands in huge contrast with today's conservative repertoire choices (Ramnarine 2011). The idea of a musical canon that binds musical works together in a seemingly coherent narrative and, in its process of becoming, sets boundaries of what is aesthetically preferable and socially excelling, is by no means a tolerant or inclusive concept. This way, the recent quest for the orchestra's legitimacy and aspired sustainability exposes a paradoxical combination of self-interested efforts to preserve the orchestra's exclusive cultural capital, and altruistic attempts to engage the orchestra in inclusive projects to shape new and wider communities (see also: Ramnarine 2011). As elaborated above, the musical canon plays a decisive role in this climate. The prominent The New York Times music critic Anthony Tommasini summarizes aphoristically:

\footnotetext{
"As long as classical music is in the preservation business, it should come as no surprise that potential new audiences (...) dismiss classical music as dated and irrelevant." (Tommasini 2001)
}

This discussion takes place in the Civil domain of the biotope. The legitimacy crisis in symphony orchestras, as seen from the viewpoint of the Civil domain, is the result of a lack of civil support for the cultural capital that classical music once represented. The second half of the twentieth century has seen a social paradigm shift that no longer takes the value of traditional cultural capital for granted (Hamel 2016; Dietachmair and Gielen 2017). In order to regain this shrinking source of legitimacy, the primary concern of musical programming in symphony 
orchestras is to broaden the civil support of the art organization. Opportunely, the institutionalization of a stable repertoire adds to the uniformity of musical tastes and conventionalization of concert practices, thereby enforcing the wider civil legitimacy of the symphony orchestra. Because of this civil acknowledgment, symphony orchestras have proved more likely to get extra money through private investments or subsidies (Kremp 2010; Glynn 2000).

Strikingly, artistic innovation remains a largely marginal practice in this climate. Marketing strategies no longer aim to innovate the content of the musical treasure house, but instead remain true to the artistic status quo by focussing on innovation of its package to assure an appeal to larger audiences (Hamel 2016). Concepts in the style of Mozart was a DJ or A candlelight evening with Chopin overflow concert programs, thereby strategically avoiding the traditional concert houses. Prominently in Europe, symphony orchestras anxiously look for financial comfort in the proximity of more popular genres, for example by providing live musicaccompaniments to blockbuster movies such as Titanic and The Lord of the Rings. The clarification of the aforementioned paradox of the musical canon lies in the fact that symphony orchestras have to play both sides in search for civil legitimacy: legitimacy is still found in the conservation of the traditional musical canon, and additional legitimacy can be acquired by means of a change of the canon's package (the concert format) and by means of the admission of the explicitly non-elitist. This 'inverted snobbism' is aimed at reestablishing a wide civil support for orchestras, and the resulting increase of ticket incomes only adds to the resulting legitimacy boost. Aesthetic issues like repertoire development as an artistic selection process, however, get sidelined.

\section{Pragmatized aesthetics}

Legitimacy crises in symphony orchestras have large repercussions on programming decisions and, accordingly, on the aesthetic profile of the orchestra. Samuel Gilmore summarizes this as follows:

"The shift of the balance of artistic resources in the contemporary concert world toward repertory programming reflects the dominance of rational aesthetic interests among concert artists and the organizational and market context in which these rational interests are cultivated." (Gilmore 1993)

Through his phrasing, Gilmore primarily stresses the impact of rational or pragmatic interests on aesthetic interests. The causal chain, however, does not end there. Pragmatic pressures ultimately affect aesthetic developments, because the exclusive adoption of the standardized musical canon ultimately leads to the marginalization of innovation and the reinforcement of the arbitrary boundaries defining 'classical music'. The aforementioned coordination problem 
between pragmatic and aesthetic interests is a vicious cycle: rational solutions to pragmatic crises may lead to crises in the aesthetic realm. The ambiguous role of the musical canon serves as a preeminent example. Legitimacy from an aesthetic point of view (e.g. the revaluation of creativity over reproduction) may in turn lead to pragmatic issues such as financial instability. An unambiguous causality between divergent legitimacy concerns in orchestras is hard to discern, and arguably impossible to establish. Manifestly though, the rationalized aesthetic shift towards artistic predictability and organizational isomorphism is prevalent in today's symphonic landscape and shows, as Glynn eloquently puts it, "how the dual chords of artistry and utility have resonated in orchestras" (Glynn 2000).

Precisely these reciprocal dynamics between often conflicting interests of symphony orchestras can be mapped out more clearly by means of the biotope model: any choice in any domain will necessarily affect the other domains as well. There is, however, one pattern that emerges in this analysis. The above inquiry thus allows me to make an additional demarcation in the biotope, that makes this mesolevel application of the model more adapted to the reallife struggle of symphony orchestras. The Domestic domain and the Peers domain, to which I earlier referred as the domains committed to research and development, can be paired in an Aesthetic Sphere. The Market domain and the Civil domain, on the other hand, both adhere to a more utilitarian logic of production and display, and thus find each other in a Pragmatic Sphere (see Figure 2).

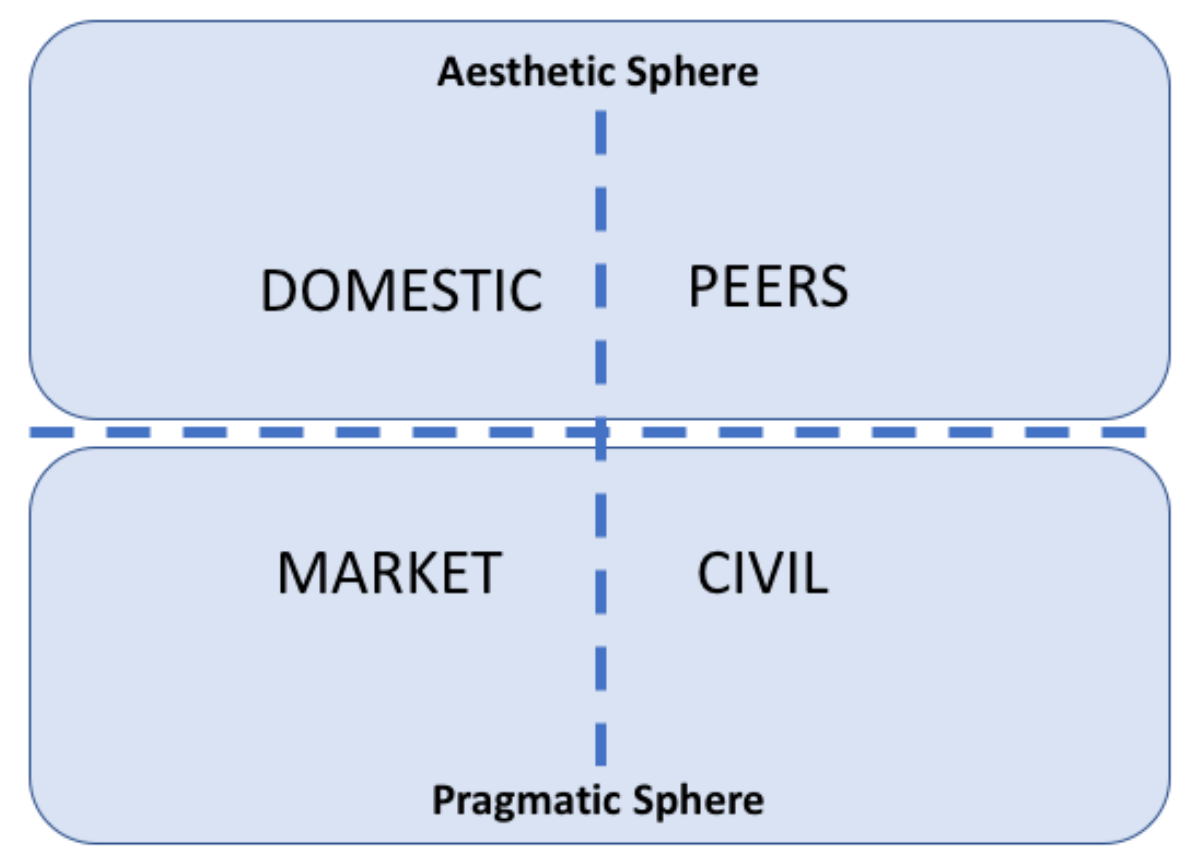

Figure 2: the biotope, its four domains and its two spheres

In light of the above analysis of rational musical programming, one can easily acknowledge that the logic of the Pragmatic Sphere currently overpowers the Aesthetic Sphere, as a somewhat paradoxical result of a legitimacy crisis in the Pragmatic Sphere. As a result, the 
Aesthetic Sphere is now largely dominated by pragmatic interests such as utilitarian predictability and civil accessibility, as shown in Figure 3. This observation is, again, an example of the way the four domains, or in this case the two spheres, are connected and regulate each other. As elaborated above, the adoption of a pragmatic logic in symphony orchestras leads to aesthetic decisions, namely the patronization of the musical canon. Legitimation from a pragmatic point of view is easily acquired: as said before, programming the canon is positively associated with increased ticket income and civil acclaim of the institution (Kremp 2010). Legitimation is far more easily bought in the Pragmatic Sphere than in the Aesthetic Sphere, because their notion of legitimacy is quantifiable. Moreover, reproduction of the established musical masterworks doesn't diametrically oppose an aesthetic logic. Rather, the result of the dominance of the Pragmatic Sphere is aesthetic compromise: the musical canon, a safe and defendable but aesthetically dead-end choice.

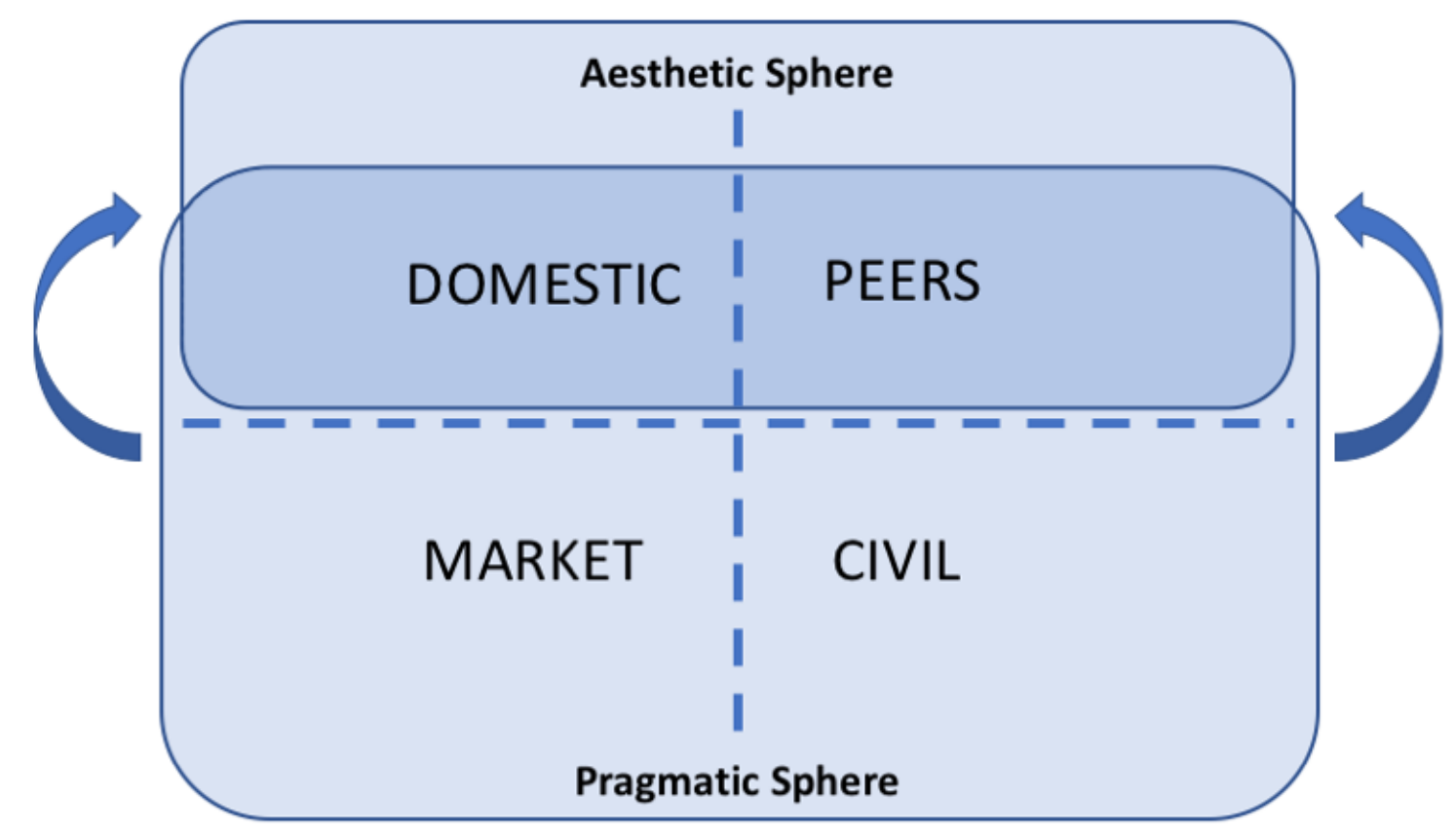

Figure 3: hybridization of the Aesthetic Sphere by the Pragmatic Sphere

This pragmatized aesthetics entails a disinterest in, and according marginalization of, aesthetic innovation. Without creative development in the Aesthetic Sphere, the Pragmatic Sphere, too, is withheld from vitalizing incentives and has to rely on the expressive potential of an aesthetic status quo, represented by the musical canon. Alex Turrini has aptly called this programming hurdle the 'long-term audience satisfaction' (Turrini, O'hare, and Borgonovi 2008): a central difficulty is to take account of the audience's comfort, but also to give them some things they do not yet think they want. Only such progressive dynamics can ensure a sustainable future for the symphony orchestra. Oppositely, the spiralwise dynamics between the domains of the biotope have regressed into an inert vicious cycle characterized by mutually reinforcing legitimacy crises. Although initially advocated as a solution to the crisis of legitimacy, 
organizational and artistic isomorphism, pre-eminently embodied by the compromise of the musical canon, became the core of the problem.

\section{Towards a sustainable solution?}

Musical programming in symphony orchestras is where both Spheres meet in a very tangible way: recognisable for the orchestra management and visible for their audiences. The ambiguous dynamics between the various domains of the biotope are mirrored in the ambiguity of empirical reality. For example, the financial picture is an ambiguous parameter in the process of musical programming, and not the only significant one. Contrary to intuition, research shows that financially secure actors are even more likely to defend traditional repertoire choices and are less inclined to innovate (Kremp 2010). Their legitimacy claim relies on symbolic cultural capital, not on financial capital. As argued above, strategic crisis management further reinforces this inclination towards traditionalism. However, the above analysis equally showed that financial security can be an empowering factor to engage in alternative programming and aesthetic innovation. Notably actors who don't rely on alreadyestablished types of cultural production, and the cultural capital associated with it, generally have more incentive to innovate (Leblebici et al. 1991), but lack the autonomy from nonartistic pressures (i.e. money) to resolutely pursue this aspiration. Such actors are bound to compromise their mission of aesthetic innovation with pragmatic survival strategies, and often remain largely peripheral. A sustainable solution is not very obvious.

A specific example of the difficulties surrounding artistic and organizational innovation can be found in Amsterdam. Since 2010, an organization called Splendor unites 50 professional musicians, performing on a regular basis in an old bathing house that was recently transformed to a professionally equipped music house. Splendor profiles itself as a peer-topeer meeting place and workspace for musicians where they can freely communicate with their audience and with each other. Repertoire and newly composed avant-garde music are equally welcomed. Splendor deliberately avoids subsidies, because they feel that their artistic freedom would be weakened in an institutionalised context with board members, managers and commercial strategists. Instead, money is raised by means of obligations, purchased by private investors, among which a few small enterprises. But their constant dependence on financial resource acquisition, and their freedom from any form of value-laden cultural capital also leaves the door open for the blind forces of the free market and aesthetic relativism. Therefore, they are strongly committed to remain peripheral, thereby reluctantly limiting their civil impact potential. Furthermore, Splendor attracts criticism as well: the fact that musicians play for very little money can be overcome because most of the musicians have well-paid jobs elsewhere, but it is also felt that their cheap concerts contaminate the music market. Their relative success might even motivate policy administrators to abandon the subsidizing system altogether. Once more, organizational structure and repertoire choices (or 
in more general terms: pragmatic and aesthetic concerns) prove to be mutually commuting factors.

\section{Conclusion}

In this article, I have tried to attune macrosociological and empirical phenomena by exploring the mesolevel balancing exercise between opposing value regimes in symphony orchestras. In today's symphony orchestras, canonical repertoire serves as a pragmatized aesthetic compromise between these tensions, as a result of increased legitimacy pressures. Both institutional and legitimacy theory points out that isomorphism and homogeneity increase perceived legitimacy, but in terms of sustainability of symphony orchestras, this phenomenon proved to be a double-edged sword. The standardized musical canon that initially promised pragmatic and aesthetic stability is now pressurized, almost ironically, because of this stability. The aura of past-ness and elitism that irrefutably sticks to the canon since its ideological appropriation, is no longer unequivocally supported by postmodern society. The musical canon is no longer a reflection of the world we live in, nor is it still the shared heritage of our present-day population. Ritualized practices, as Botstein's provocative remark hinted at, alienate potential audiences from the art form and reinforce the pervasive anxiety that symphonic music has outlived its role. Initial benefits notwithstanding, the dominant logic of canonization has become an inert vicious cycle maintained by mutually reinforcing legitimacy crises. I have argued that the canon is an aesthetic form but also implies an organizational form with according practices. Cultural homogeneity and organizational isomorphism go hand in hand.

In that line of thought, a symphony orchestra that aspires towards a sustainable future shows itself as an active cultural body, not merely as an acoustic museum for cultural heritage. The challenge for the future is to explore modes of development, both in organizational form of the symphony orchestra and in its products, in which the aesthetic is enabled to grow along. In order to truly reach out to larger communities, and fully use the orchestra's impact potential, new repertoires and corresponding cultural contexts need to be developed. In short: to revitalize the repertoire amounts to revitalizing the orchestra's performativity and to rendering any explicit legitimacy claim superfluous.

The biotope proved its analytical value in two ways. Firstly, the biotope allowed us to reintroduce a level of complexity into this discourse. The ambiguous effects of subsidizing logic and the short- and long-term consequences of isomorphism can be adequately understood in this flexible model. As such, the biotope functioned as an organizational anatomy lab: "if I pull this string in this domain, what are the expected effects throughout the biotope as a whole?". The biotope equally suggested that there are various modalities of sustainability and various 
strategies to achieve and align those. The interdependence of these modalities is a crucial insight: in the long run, the pragmatic cannot do without the aesthetic, and vice versa.

Secondly, this layer of complexity showed that processes explaining why orchestras would depart from tradition and turn to innovation, are not well understood, which allowed us to uncover pseudo-solutions for unsustainability. The organizational and artistic isomorphism embodied by the musical canon, to which I referred as the pragmatized aesthetic compromise, grants temporary stability (that's how the whole idea of a musical canon came into being), but an overemphasis reinforces the legitimacy crisis on the long run: isomorphism and uniformity is often associated with redundancy. The eminent similarity between orchestras worldwide provide an all-too-easy argument for policy makers and public opinion to make existing orchestras merge or cut off their financial lifelines, and it is hard to prove them wrong. The mutually interdependent domains of the biotope may help to arrange an efficient and sustainable alignment of divergent interests in the art world, and make art accessible to audiences without compromising artistic integrity. In the end, it may even suggest how an art organization such as the symphony orchestra can once more offer resistance to the macrosociological changes on which it depends so heavily.

Allmendinger, Jutta, and J. Richard Hackman. 1996. "Organizations in Changing Environments: The Case of East German Symphony Orchestras." Administrative Science Quarterly 41 (3): 337-69. https://doi.org/10.2307/2393935.

Becker, Howard. 1984. Art Worlds. University of California Press.

Becker, Howard S. 1974. "Art As Collective Action." American Sociological Review 39 (6): 767-76. https://doi.org/10.2307/2094151.

Bergeron, Catherin, and Philip V. Bohlman. 1992. Disciplining Music; Musicology and Its Canons. Chicago: The University of Chicago Press.

Botstein, Leon. 1996. "The Future of the Orchestra." The Musical Quarterly, Orchestra Issue, 2 (80): 189-93.

- - . 1998. "Toward a History of Listening." The Musical Quarterly 82 (3/4): 427-31.

Bourdieu, Pierre. 1986. "The Forms of Capital." In Handbook of Theory and Research for the Sociology of Education, edited by J. Richardson, 241-58. New York: Greenwood.

Dietachmair, Philipp, and Pascal Gielen, eds. 2017. The Art of Civil Action: Political Space and Cultural Dissent. 01 edition. Amsterdam: Valiz.

DiMaggio, Paul. 1991. "Social Structure, Institutions, and Cultural Goods: The Case of the United States." In Social Theory for a Changing Society, edited by Pierre Bourdieu and P Coleman, 133-55. Boulder, Colorado: Westview Press.

DiMaggio, Paul, and Walter Powell. 1983. "The Iron Cage Revisited Institutional Isomorphism and Collective Rationality in Organizational Fields : Economics Meets Sociology in Strategic Management." American Sociological Review 48: 147-60.

Flanagan, R. J. 2012. The Perilous Life of Symphony Orchestras. Yale University Press.

Galinsky, Adam D., and Erin V. Lehman. 1995. "Emergence, Divergence, Convergence: Three 
Models of Symphony Orchestras at the Crossroads." The European Journal of Cultural Policy 2 (1): 117-39. https://doi.org/10.1080/10286639509358005.

Gielen, Pascal. 2009. The murmuring of the artistic mulitude Global Art, Memory and PostFordism. Valiz. https://surfsharekit.nl/publiek/fontys/733d1cc5-23d2-47ca-a6bb44bdf2a14e96.

- - . 2010. "The Art Institution in a Globalizing World." The Journal of Arts Management, Law, and Society 40 (4): 279-96. https://doi.org/10.1080/10632921.2010.525065.

Gilmore, Samuel. 1993. "Tradition and Novelty in Concert Programming: Bringing the Artist Back into Cultural Analysis." Sociological Forum 8 (2): 221-42.

https://doi.org/10.1007/BF01115491.

Glynn, Mary Ann. 2000. "When Cymbals Become Symbols: Conflict Over Organizational Identity Within a Symphony Orchestra." Organization Science 11 (3): 285-98. https://doi.org/10.1287/orsc.11.3.285.12496.

- - . 2002. "Chord and Discord: Organizational Crisis, Institutional Shifts, and the Musical Canon of the Symphony." Poetics 30 (1): 63-85. https://doi.org/10.1016/S0304-

422X(02)00004-9.

Hamel, Micha. 2016. Speelruimte Voor Klassieke Muziek in de 21e Eeuw. Codarts Rotterdam. Hasitschka, Werner, Peter Goldsleger, and Tasos Zembylas. 2005. "Cultural Institutions Studies: Investigating the Transformation of Cultural Goods." The Journal of Arts Management, Law, and Society 35 (2): 147-58. https://doi.org/10.3200/JAML.35.2.147-158. Kraatz, Matthew, and Emily Block. 2008. "Organizational Implications of Institutional Pluralism." In The SAGE Handbook of Organizational Institutionalism, edited by Royston Greenwood and Christine Oliver. SAGE.

Kremp, Pierre-Antoine. 2010. "Innovation and Selection: Symphony Orchestras and the Construction of the Musical Canon in the United States (1879-1959)." Social Forces 3 (88): 1051-82.

Leblebici, Huseyin, Gerald R. Salancik, Anne Copay, and Tom King. 1991. "Institutional Change and the Transformation of Interorganizational Fields: An Organizational History of the U.S. Radio Broadcasting Industry." Administrative Science Quarterly 36 (3): 333-63. https://doi.org/10.2307/2393200.

Osborne, William. 1999. "Symphony Orchestras and Artist-Prophets: Cultural Isomorphism and the Allocation of Power in Music." Leonardo Music Journal, Power and Responsibility: Politics, Identity and Technology in Music, , no. 9: 69-75.

Ramnarine, Tina K. 2011. "The Orchestration of Civil Society: Community and Conscience in Symphony Orchestras." Ethnomusicology Forum 20 (3): 327-51.

https://doi.org/10.1080/17411912.2011.638515.

- - . , ed. 2018. Global Perspectives on Orchestras: Collective Creativity and Social Agency. Studies in Musical Performance as Creative Practice. Oxford, New York: Oxford University Press.

Sigurjonsson, Njordur. 2010. “Orchestra Audience Development and the Aesthetics of 'Customer Comfort.'” The Journal of Arts Management, Law, and Society 40 (4): 266-78. https://doi.org/10.1080/10632921.2010.502011.

Suchman, Mark C. 1995. "Managing Legitimacy: Strategic and Institutional Approaches." Academy of Management Review 20 (3): 571-610.

https://doi.org/10.5465/AMR.1995.9508080331.

Tommasini, Anthony. 2001. "What's New in Classical Music? Not Much." The New York Times, April 29, 2001, sec. Arts. https://www.nytimes.com/2001/04/29/arts/music-what-s- 
new-in-classical-music-not-much.html.

Turrini, Alex, Michael O'hare, and Francesca Borgonovi. 2008. "The Border Conflict between the Present and the Past: Programming Classical Music and Opera." The Journal of Arts Management, Law, and Society 38 (1): 71-88. https://doi.org/10.3200/JAML.38.1.71-88. Vandyck, Koen. 2016. "Naar Een Veerkrachtig Vlaams Orkestenlandschap." Weber, William. 1999. "The History of Musical Canon." Rethinking Music, 340-58. - - . 2002. "Consequences of Canon: The Institutionalization of Enmity between Contemporary and Classical Music." Common Knowledge 9 (1): 78-99.

Zembylas, Tasos. 2004. "Art and Public Conflict: Notes on the Social Negotiation of the Concept of Art." The Journal of Arts Management, Law, and Society 34 (2): 119-32. https://doi.org/10.3200/JAML.34.2.119-132. 